\title{
EXTRANJERAS Y ESPAÑOLAS EN UNA COLONIZACIÓN AGRARIA. LAS MUJERES EN LAS NUEVAS POBLACIONES DE SIERRA MORENA Y ANDALUCÍA (SIGLO XVIII)
}

\author{
Adolfo Hamer-Flores \\ Universidad Loyola Andalucía \\ ahamer@uloyola.es
}

\begin{abstract}
RESUMEN: El campo historiográfico centrado en mujer, familia o vida cotidiana constituye para el caso concreto de las Nuevas Poblaciones de Sierra Morena y Andalucía casi un verdadero páramo. Las investigaciones han sido escasas y de calidad muy desigual a pesar de que las mujeres constituyeron la mitad de la población o de que es difícil evaluar el grado de éxito de una colonización agraria sin conocer los principales rasgos de su existencia. Es por ello por lo que nuestro objetivo aquí consistirá en realizar una aproximación a esas mujeres, tanto extranjeras como españolas, protagonistas de la colonización a través de tres grandes indicadores: su papel en la sociedad, su adaptación a un entorno muy diferente y su imagen en elementos artísticos.
\end{abstract}

Palabras clave: mujeres, inmigración, repoblación, Pablo de Olavide, Ilustración.

\section{FOREIGN AND SPANISH WOMEN IN AN AGRARIAN COLONIZATION. WOMEN IN THE NEW SETTLEMENTS OF SIERRA MORENA AND ANDALUSIA (18 ${ }^{\text {TH }}$ CENTURY)}

\footnotetext{
ABSTRACT: The historiographic field centered on women, family or daily life constitutes, for the specific case of the New Settlements of Sierra Morena and Andalusia, almost a true wasteland. Research has been scarce and of very unequal quality despite the fact that women constituted half of the population or that it is difficult to evaluate the degree of success of an agrarian colonization without knowing the main features of its existence. That is why our objective
} 
here is to make an approach to these women, both foreign and Spanish, protagonists of colonization through three major indicators: their role in society, their adaptation to a very different environment and their image in artistic elements.

Keywords: Women, inmigration, repopulation, Pablo de Olavide, Enlightment.

Recibido: 30 de abril de 2019

Aceptado: 16 de junio de 2019

\section{Introducción}

Los estudios que hasta la fecha se han ocupado del componente humano en las Nuevas Poblaciones de Sierra Morena y Andalucía han venido centrando su atención preferentemente en ofrecer datos sobre la procedencia, evolución demográfica y distribución de los inmigrantes en el territorio, dejando a un lado otros temas como el papel de la mujer, la familia y la vida cotidiana en esa nueva sociedad agraria. Una realidad que no pasa desapercibida para la historiografía y de la que se hacía eco recientemente la profesora Gómez Navarro ${ }^{1}$. Tanto es así que el grueso de trabajos que se han centrado parcial o totalmente en las mujeres en las Nuevas Poblaciones solo han abordado el tema a partir de reflexiones genéricas (con escasas referencias a las colonias) o recurriendo a hechos puntuales que no se integran en un discurso global; no faltando incluso alguno que, amén de no aportar nada nuevo, defiende ideas sin ningún tipo de base documental, como sostener que las colonas desempeñaban un trabajo no remunerado en las actividades artesanales impulsadas por la administración ${ }^{2}$.

En cualquier caso, somos conscientes de que esta falta de estudios sobre las mujeres debe mucho a las limitaciones de las fuentes primarias disponibles hoy para el investigador. Las considerables mermas sufridas en el último cuarto de milenio en la casi totalidad de archivos que contenían documentación sobre las nuevas colonias obligan al historiador a realizar un análisis extensivo e intensivo de la escasa documentación conservada. Sin esta lenta, compleja y tediosa labor cualquier nueva aportación se verá expuesta en el peor de los casos a ser un mero resumen, con más o menos errores en función del nivel de conocimiento de la historia neopoblacional, y en el mejor de los casos a ser un trabajo fuertemente condicionado por los testimonios puntuales y aleatorios

1. Gómez Navarro, S., "Aportación para una doble efeméride: Carlos III y su obra colonizadora en las prensas. Un estado de la cuestión". Revista de Historiografía 27 (2017), pp. 379-381.

2. Vacas Campos, S. M. y Vacas del Campo, J. A., "Las mujeres en las Nuevas Poblaciones", Congreso Internacional Nuevas Poblaciones de Sierra Morena y Andalucía y otras colonizaciones agrarias en la Europa de la Ilustración. Jaén 2018, p. 1481. 
que recojan los estudios previos. Unos testimonios que, en cualquier caso, no pretendemos desmerecer ya que, sumados a otros aún inéditos, nos permitirán alcanzar unas conclusiones más cercanas a la realidad histórica ${ }^{3}$. Resta mucho por hacer todavía, lo cual no impide que consideremos útil y necesario ofrecer a la comunidad científica algunas conclusiones sobre aquellos aspectos en los que más se ha avanzado; algo que, a la par, puede servir de aliciente para trabajos ulteriores.

Es por ello por lo que en esta investigación nos hemos marcado como objetivo fundamental el dar algunas respuestas a tres cuestiones con una importancia fuera de toda dura y, en cierta medida, muy desatendidas por la historiografía neopoblacional. En primer lugar, queremos analizar el papel que la administración, en especial Pablo de Olavide ${ }^{4}$, como primer superintendente y responsable de su puesta en marcha entre 1767 y 1776, quiso darles en estas nuevas colonias agrarias; en segundo lugar, abordaremos la difícil adaptación de la mujer, especialmente las originarias de Centroeuropa, a un espacio creado ex novo y, finalmente, en último lugar estudiaremos si las mujeres están presentes, y cómo se las muestra, en las representaciones artísticas coetáneas que han llegado a nuestros días.

Con las respuestas a estos interrogantes consideramos que estaremos en disposición de contextualizar mejor en la historia del siglo XVIII español el fenómeno de las Nuevas Poblaciones de Sierra Morena y Andalucía, donde tendrían lugar procesos y situaciones muy diferentes a las de su entorno geográfico inmediato y que, en ocasiones, significaron una verdadera apuesta, aunque se frustrase, por una profunda reforma de la realidad contemporánea.

\section{Las mujeres en las Nuevas Poblaciones: ecos del pensamiento de Olavide}

Aunque el feminismo y una de las iniciativas más conocidas a favor de la reivindicación de la mujer tienen sus orígenes en el siglo XVIII (nos referimos

3. En este sentido, queremos destacar el extraordinario valor de los testimonios de archivo recopilados por Carlos Sánchez-Batalla (Sánchez-Batalla Martínez, C., "Mujer, familia y vida cotidiana en las Nuevas Poblaciones", Mujer, familia y sociedad en las Nuevas Poblaciones. Actas del IV Congreso Histórico sobre Nuevas Poblaciones. La Carolina 1996, pp. 37-72), tan significativos que prácticamente constituyen el hilo vertebrador de la mayor parte de los trabajos que se ocupan del papel de la mujer en las Nuevas Poblaciones de Sierra Morena y Andalucía, incluido el estudio más reciente del que disponemos: Reder Gadow, M., "La mujer, protagonista en las Nuevas Poblaciones de Carlos III", Congreso Internacional Nuevas Poblaciones de Sierra Morena y Andalucía y otras colonizaciones agrarias en la Europa de la Ilustración. Jaén 2018, pp. 1549-1567.

4. Sobre el limeño Pablo de Olavide es imprescindible la consulta de las dos obras que mejor plasman su recorrido biográfico: Defourneaux, M., Pablo de Olavide, el afrancesado. México 1965; y Perdices de Blas, L., Pablo de Olavide (1725-1803), el ilustrado. Madrid 1992. 
a la Vindicación de los derechos de la mujer de Mary Wollstonecraft ${ }^{5}$ ), la percepción de los ilustrados acerca del rol femenino no implicaba en modo alguno una igualdad con el hombre como la entendemos hoy. Así pues, el pensamiento de Pablo de Olavide y las iniciativas desarrolladas en las Nuevas Poblaciones, aunque no puede negarse su carácter avanzado para la época, se enmarcan necesariamente en esta misma línea ilustrada. En las tertulias del limeño -incluidas las que celebraba cuando estaba en las Nuevas Poblaciones- participaban mujeres, como su esposa Isabel de los Ríos o su prima Gracia de Olavide ${ }^{6}$, pero aun así este pensaba que la formación femenina era necesaria sobre todo por su influencia y no per se; literalmente sostenía que "si las mujeres estuvieran bien educadas, lo estarían muy presto los hombres, pues desestimarían a los que careciesen de educación (...) ¿qué hombre no quisiera instruirse si se viere entre mujeres que se burlasen de su ignorancia y grosería?"7 . La educación de la mujer constituía más un instrumento para garantizar un sector masculino aplicado y trabajador (pues de un modo u otro en este recaían los cargos de gobierno y administración, así como la mayor parte de las iniciativas económicas en el sector privado) que una pretensión apoyada en la creencia en una igualdad de derechos y oportunidades entre hombres y mujeres. Estas ideas comenzarían a circular ampliamente solo muchas décadas más tarde.

En una sociedad preindustrial y agraria como la neopoblacional, la importancia que se concedió a la formación se limitó, en esta misma línea, a tratar de garantizar la adquisición de unos conocimientos básicos por parte de niños y niñas. Lo cual no es poco, pues no puede perderse de vista lo avanzado que fue para la época el artículo 74 del Fuero de Población ${ }^{8}$ de 1767 disponiendo la obligatoriedad de la enseñanza primaria en las nuevas colonias para todos los niños ${ }^{9}$. No ocurrió lo mismo, en cambio, en lo que respecta a la participación

5. Wollstonecraft, M., A vindication of the rights of woman; with strictures on political and moral subjects. Boston 1792.

6. Rodríguez-Moñino Soriano, R., "Presencia de la mujer en las Nuevas Poblaciones de Sierra Morena y Andalucía". Boletín del Instituto de Estudios Giennenses 160 (1996), p. 11.

7. Perdices de Blas, L., "Mujeres, educación y mercado de trabajo en el proyecto reformista de Pablo de Olavide", ICE. Revista de Economía 852 (enero-febrero 2010), p. 106.

8. Novísima Recopilación de las leyes de España, Madrid, 1805, tomo III, Libro VII, Título XXII, Ley II, 487-493. En esta edición se suprimieron veinte artículos, para consultar el texto completo véase Hamer Flores, A. (ed.), Legislación Histórica Neopoblacional. Disposiciones normativas emanadas del poder central en las Nuevas Poblaciones de Sierra Morena y Andalucía (1767-1835). Madrid 2018, pp. 55-77.

9. La aplicación práctica de esta disposición chocó con no pocos inconvenientes entre los que podemos destacar el poblamiento disperso (los niños y niñas que vivían alejados de los núcleos urbanos donde se ubicaban las escuelas no tuvieron fácil el poder asistir a clase) y la falta de buenos maestros, por no mencionar que tras la caída de Olavide la educación nunca fue un asunto prioritario para las autoridades neopoblacionales. 
de la mujer en la economía productiva ${ }^{10}$, pues en este ámbito sí se mostraría mayor interés, algo que se plasmó en el propio Fuero al mencionar la conveniencia de fomentar lo que hoy conocemos como industria popular (artículo 43). A Olavide le sorprendía mucho que las mujeres andaluzas, incluso en el caso de ser sus maridos jornaleros, con lo que cualquier ingreso extra siempre era necesario, no solían trabajar fuera de sus casas para mejorar los ingresos familiares; incluso estaba mal visto socialmente que las mujeres casadas trabajasen ${ }^{11}$. El 29 de noviembre de 1773 informaba a Miguel de Múzquiz, secretario de Estado y del Despacho de Hacienda, que las colonas alemanas estaban acostumbradas a trabajar en sus países y que no era conveniente que adoptasen el carácter ocioso de las españolas, de ahí su decidida apuesta por que las mujeres en las Nuevas Poblaciones participaran en las actividades agrarias y artesanales. Especial atención dedicó a estas últimas, pues reducirían la dependencia de las importaciones extranjeras ${ }^{12}$ y complementarían la economía agraria (pues "la agricultura sola está expuesta a sufrir mucho en malos años"), con la instalación de dos tipos de industrias para ocupar básicamente a las mujeres: una popular (consistente en el hilado y torcido de géneros bastos) y otra urbana (con la creación de algunas fábricas en los núcleos urbanos más importantes, sobre todo en La Carolina); se daba preferencia a la de tipo popular, pues sin tener "los géneros comunes baratos y propios para surtir al pueblo a precios cómodos (...) le parecía poco cuerdo pensar en fábricas finas y $\operatorname{costosas}^{\prime \prime 13}$. Unas iniciativas que estuvieron en completa sintonía con las ideas que circulaban entonces en el Consejo de Castilla por la facilidad con la que podían difundirse entre el sector femenino no

10. Ni que decir tiene que no es nuestra intención minusvalorar todas las tareas que las mujeres desempeñaban en el entorno doméstico, cuyas fronteras eran ciertamente muy difusas pues iban más allá de mantener el hogar y la ropa limpias o de preparar la comida. Estas labores, sin ningún género de duda, ocupaban gran parte de su jornada diaria y también contribuían, aunque siempre se tienda a considerarlas como complementarias a las del sector masculino, a esa economía productiva.

11. Consideramos que las convenciones sociales que establecían lo que era correcto y lo que no lo era actuaban de manera determinante en el mundo del trabajo femenino, con independencia de la voluntad que tuvieran las mujeres para trabajar. Aunque con ligereza, o tal vez con la intención de remarcar la laboriosidad de las colonas, Olavide y otros tildan de perezosas a las españolas del sur peninsular, lo cierto es que el entorno actuaría como un factor limitante más de la escasa autonomía que ya tenían en el espacio público.

12. El superintendente Olavide sostiene que procuró establecer "telares de albornoces, estameñas y barraganes, que son los géneros de que se viste comúnmente la Nación y que por la mayor parte vienen de Inglaterra con mucho perjuicio de España".

13. Archivo General de Simancas -en adelante AGS-, Secretaría y Superintendencia de Hacienda, leg. 498, doc. 332. Olavide le informaría en otra ocasión acerca de que ha hecho lo posible por "poner la ociosidad en infamia, y en estimación al honesto trabajo. Me ha costado mucha pena porque tenía que luchar contra la costumbre envejecida de todos los pueblos comarcanos que se reían de ver trabajar a las alemanas" (AGS, Secretaría y Superintendencia de Hacienda, leg. 498, doc. 330. Carta de Olavide a Múzquiz de 30 de octubre de 1773). 
solo de las colonias sino también del resto de la Corona ${ }^{14}$. Buena prueba de ello será que se mencione como ejemplo a las Nuevas Poblaciones en el libro que Pedro Rodríguez de Campomanes, fiscal del referido Consejo, publicó en 1774 con el título de Discurso sobre el fomento de la industria popular ${ }^{15}$, y del que la Real Hacienda pagaría una considerable tirada de 30.000 ejemplares con el objetivo de que estas experiencias llegasen a conocimiento del mayor número de personas posible, especialmente miembros de la administración. Un propósito de todo punto exitoso pues es la obra española de naturaleza económica más traducida y difundida fuera de nuestras fronteras en el siglo XVIII' ${ }^{16}$.

No obstante, la detención y el posterior autillo de fe inquisitorial contra Pablo de Olavide supusieron el inicio del declive de estas actividades artesanales en las colonias y el fin de buena parte de las medidas que trataban de incorporar a la mujer al mercado laboral. Casi desde el inicio, los detractores de sus ideas no dudaron en acusarlo de atentar contra el orden social al generar situaciones de riesgo para la seguridad y moral pública, pues algunas de las jóvenes que ayudaban a sus familias cuidando los ganados fueron objeto de agresiones y hasta de estupros. La presencia de la mujer en el espacio público debía volver, también en las colonias, a lo que la sociedad del momento dictaba; lo cual no impediría que las autoridades neopoblacionales intentaran en las décadas siguientes, siendo fieles a lo consignado en el propio Fuero, que las hijas y mujeres de los colonos se aplicasen en trabajos honestos y útiles y no permanecieran ociosas, aconsejando que estas se empleasen en las fábricas textiles $^{17}$. En cualquier caso, el rol femenino en el espacio laboral nunca volvería

14. El éxito de este pensamiento fue muy limitado. En este sentido, solo nos consta lo que algunos funcionarios de las nuevas poblaciones de Sierra Morena explicaron al rey sobre las mujeres de los pueblos vecinos, "que antes no hacían nada, [y] van hoy a las colonias, toman el lino o la lana y la devuelven hilada, de modo que la actividad que hay en ellas se ha difundido en los lugares confinantes y es de esperar que se propague a todos"; o la influencia que tuvieron estas prácticas en el primer subdelegado de estas colonias, Miguel de Jijón, quien instaló en Málaga una fábrica de hilados en la que solo trabajaban mujeres y a la que denominó Carolina Malagueña (Sánchez-Batalla Martínez, C., Aldeaquemada: naturaleza, arte e historia. Prehistoria a 1835. Jaén 1996, p. 193).

15. Discurso sobre el fomento de la industria popular. Madrid 1774, pp. 132-133.

16. Lluch, E. y Argemí, L, "Genealogía teórica e influencia práctica del Discurso sobre el fomento de la industria popular (1774)". Revista de Historia Industrial 3 (1993), p. 179. De la considerable dimensión de esta tirada da buena cuenta que solo se imprimieran 4.000 ejemplares de la obra que Campomanes finalizó en 1775 con el título de Discurso sobre la educación popular de los artesanos y su fomento.

17. Hamer Flores, A., "Orden y vida cotidiana en la Intendencia de las Nuevas Poblaciones de Sierra Morena y Andalucía. El frustrado auto de buen gobierno de 1801". Codex. Boletín de la Ilustre Sociedad Andaluza de Estudios Histórico-Jurídicos VI-VII (2014-2016), p. 153. Este deseo lo manifiesta el intendente Tomás José González Carvajal en 1801, concretamente en el artículo 15 del auto de bueno gobierno que trató de aplicar por entonces en las nuevas colonias. 
a recuperar los niveles alcanzados durante la superintendencia de Olavide, una circunstancia que no es óbice para que dispongamos de algún caso llamativo como la inclusión de algunas mujeres en la guardia cívica de colonias de escasa población en momentos de necesidad ${ }^{18}$ o el que una de ellas se ocupase de la portería de las oficinas de la Subdelegación de las Nuevas Poblaciones de Andalucía en 1823 y $1824^{19}$. Lamentablemente, desconocemos el contexto en el que esta última accedió a dicho empleo, pero el hecho de que no se tratase de un episodio breve parece ponernos en la pista de que fue su buen hacer el que le permitió mantenerlo.

La difusión en los primeros años de telares de lienzos caseros y el trabajo en las fábricas, que se procuró que no solo fueran de distintos géneros textiles sino también de otros productos como loza fina y basta o peltre, no impidió que las mujeres también tuvieran un papel destacado en el sector agrario. Sus tareas en las nuevas colonias, con independencia de que fueran de origen español o extranjero, no eran muy diferentes a las que desempeñaba el sector femenino en otros lugares comarcanos, lo que verdaderamente suponía una particularidad era la posibilidad potencial de contar con un elevado número de mujeres como propietarias al frente de explotaciones agrarias de tamaño medio. Siempre que tuvieran padres o maridos fueron estos los que las gestionaron en su nombre, pero, en teoría, eran libres de disponer de esos bienes con el visto bueno de aquellos durante su vida y sin necesidad de este en sus últimas voluntades. Como cabía esperar, la administración rara vez concedería una suerte de tierra a una mujer, salvo excepciones como algunas solteras, quizá en situación de vulnerabilidad por orfandad o similar, para facilitar que contrajeran matrimonio ${ }^{20}$ o como madres viudas con hijos aún menores de edad que ya pudieran hacerse cargo de su cultivo o que gestionaran estas labores mientras no estuvieran aque-

18. Este fue el caso de la guardia cívica que hubo que formar en Aldeaquemada a finales de 1800 para impedir la entrada de forasteros que pudieran contagiar la fiebre amarilla, y de la que formaron parte las colonas Bárbara Dekelmayerin, Mariana Leivin y Bárbara Fetez (Sánchez-Batalla Martínez, C., Aldeaquemada: naturaleza..., p. 193.

19. Archivo General del Ayuntamiento de La Carlota -en adelante AGALC-, Subdelegación de La Carlota, caja 1232, exp. 11, docs. 1 y 2. El nombre de esta empleada era Catalina Fernández. En lo que respecta al salario que percibía carecemos de información, pero es probable que estuviera en la línea de los 2190 reales anuales que recibía su homólogo en las oficinas de La Carolina en 1820 (Bernaldo de Quirós, C., Colonización y subversión en la Andalucía de los s. XVIII-XIX. Barcelona 1986, p. 139).

20. Este parece ser el caso de la colona Bárbara Kidsin que, estando soltera, aparece como propietaria de la suerte 82 del $4^{\circ}$ Departamento de Carboneros en 1781 (Archivo Histórico Provincial de Jaén -en adelante AHPJ-, Hacienda, Colonización de Sierra Morena, libro 8005, f. 66r) y de la huérfana Catalina Bernier, a quien el subdelegado Fernando de Quintanilla le concedió la suerte número 39 del $2^{\circ}$ Departamento de San Sebastián de los Ballesteros como ayuda para que pudiera contraer matrimonio (AGS, Secretaría y Superintendencia de Hacienda, leg. 501, doc. 168). 
Ilos en disposición de hacerlo ${ }^{21}$. Un hecho que no era incompatible con que las mujeres pudieran heredar o comprar propiedades, aunque ciertamente en el caso de herencias esto no solía ocurrir mientras que hubiera hermanos varones sin dotación.

El artículo 62 del Fuero implantaba un sistema hereditario en la transmisión de la propiedad, favoreciendo a los hijos frente a las hijas; estas últimas solo tendrían opciones en caso de no contar con hermanos varones y estar casadas con labrador útil ${ }^{22}$. No obstante, la praxis fue algo más compleja ${ }^{23}$. Cuando el heredero de la dotación de tierra tenía ya otra propiedad, este podía elegir entre quedarse con la que disfrutaba o renunciar a ella y heredar la que le correspondía; en el primer caso, esa propiedad pasaba automáticamente al siguiente heredero varón y, si no existía, a la hermana de mayor edad. Ahora bien, hubo ciertamente un modo indirecto de burlar el restrictivo sistema de acceso a la propiedad por herencia, consentido por la administración, y que se apoyaba en la posibilidad de adquirirla por compra. Este fenómeno estuvo vinculado en algunos casos al deseo de los progenitores de no dejar desamparados a los hijos e hijas que no iban a heredar una dotación, recibiendo permiso para comprar las que pudieran adquirir para dotarlos y adquiriendo el compromiso de que dispusiesen de la correspondiente yunta para su cultivo ${ }^{24}$.

21. Estos casos no fueron en verdad muy abundantes, pero algunos de ellos Ilaman nuestra atención. Nada más llegar a España en 1769, a la viuda Otilde Toniel se le adjudicó el 1 de junio la suerte número 85 de la colonia de Fuente Palmera, a pesar de que solo vino acompañada por una hija de doce años y un hijo de seis (AGALC, Subdelegación de La Carlota, caja 1232, exp. 7).

22. Aunque el cumplimiento de la instrucción que Olavide dictó en septiembre de 1770 no fue más allá de su etapa al frente de las Nuevas Poblaciones, consideramos muy significativo el firme deseo que mostró siempre el superintendente de vincular la posesión de estas propiedades con la formación de una unidad familiar. En esta disposición mandaba que, al carecer de herederos forzosos, el colono o colona podía dejar en herencia su suerte a un varón que contase, al menos, con 17 años o a una mujer con 12 años cumplidos; siendo forzoso que en ambos casos contrajesen matrimonio en el periodo máximo de un año a partir de la fecha en la que entrasen en posesión de dicha explotación, siendo nula y de ningún efecto dicha sucesión si no cumplían este precepto (Archivo Histórico Nacional -en adelante AHN-, Inquisición, leg. 3603, s.f.).

23. Al tratarse de un fenómeno generalizado en todas las colonias es inviable ofrecer aquí todas las referencias archivísticas. En cualquier caso, mencionaremos la fuente que más casos muestra para un periodo de tiempo muy extenso: la historia de las suertes de Fuente Palmera, que nos informa de todas las propiedades de esta feligresía para la etapa comprendida entre 1771 y 1833 (Archivo Municipal de Fuente Palmera -en adelante AMFP-, Comandancia Civil de Fuente Palmera, tomo II, s.f.).

24. Esta circunstancia explica que los progenitores, tanto padres como madres, procurasen a sus hijos esas yuntas de labor. Al tratarse de una acción estrictamente privada, apenas contamos con testimonios que nos permitan conocer si existieron patrones comunes en el modo de hacer posible que dispusieran de ellas; aun así, no son infrecuentes, en los documentos de última voluntad, las referencias a que se considerasen estas cantidades in- 
Dado que las suertes no podían dividirse ni acumularse, no era infrecuente que los progenitores procurasen obtener los permisos necesarios para legar esas dotaciones de tal modo que se evitase, en la medida de lo posible, que alguno de los hijos quedase sin dotación; si su cónyuge no era ya propietario o no le correspondía heredar alguna propiedad, en esos casos, con independencia de que fuesen hijos o hijas, los progenitores trataban de garantizarles un medio para su subsistencia. Aún más, tampoco fueron infrecuentes los casos en los que mujeres adultas emplearon todo o parte de la herencia de sus progenitores, o de algún pariente, para adquirir alguna propiedad rústica, aunque fuese una senara en los ruedos de una colonia o aldea.

Mención especial merece el caso de la viudez. La falta de una regulación clara llevó a diferentes modos de proceder por parte de la administración cuando una colona enviudaba, lo cual generó no pocas disputas y procedimientos judiciales. En los primeros años de la colonización parece que la práctica más habitual era que al morir el propietario de la suerte o de la senara, siempre que no hubiera dispuesto algo diferente en su testamento, las heredaran sus hijos en caso de tenerlos; solo cuando aún eran menores de edad la viuda quedaría como tutora, siempre con la supervisión del padre de menores de las colonias, gestionando dichos bienes hasta que fueran mayores. Una situación que las hacía depender económicamente, a partir de ese momento, de sus hijos o hijastros, llevándolas en no pocas ocasiones a pensar en contraer un nuevo matrimonio ${ }^{25}$. Esta práctica se consideró lesiva para los intereses de muchas de esas colonas, sobre todo en los casos en los que las propiedades se habían concedido por el gobierno cuando ya estaban casadas, por lo que se fijaría la posibilidad de que, aunque tuvieran hijos, las esposas pudieran disfrutar mientras vivieran en estado de viudez del usufructo de la totalidad o parte de esas propiedades. A modo de ejemplo de esta última realidad incluiremos a continuación lo que declaraba el colono alsaciano Juan Jacobo Wick ${ }^{26}$ en tu testamento, otorgado en La Carlota en 1814:

vertidas en compra de suertes y yuntas o en las dotes de las hijas como parte de la legítima que les correspondía heredar. Muy diferente era al caso de las madres viudas con hijos menores, pues la administración neopoblacional supervisaba estas inversiones a través de la figura del padre de menores. Un ejemplo de esta última realidad nos lo proporciona la escritura de fianza que otorgó en marzo de 1807 la colona viuda María Naranjo, vecina de Fuente Palmera, por la cantidad de 882 reales y 17 maravedíes para la yunta de dotación de su hijo menor Sebastián Nadales (ANPO, La Carlota, Escribano Miguel Muños, prot. 946, año 1807 , f. 50r y v).

25. Perdices de Blas, L., "Mujeres, educación y mercado de trabajo...". ICE. Revista de Economía 852 (enero-febrero 2010), p. 110.

26. Indicamos al lector que tanto aquí como en los restantes apartados y notas al pie de esta investigación hemos consignado los nombres y apellidos de los individuos tal y como aparecen en los documentos de archivo, aun siendo conscientes de que la forma en la que se plasman no se ajusta a la forma correcta que tendrían en alemán o francés. 
(...) declaro que la suerte que poseo en este $\left[2^{\circ}\right]$ Departamento se donó por el gobierno a la citada mi mujer [Anne Marie Claude] y a mí, por cuya razón y atención a la orden de Su Majestad para que a las viudas se les mantenga en la posesión de las suertes, lo hago así presente para que conste y a consecuencia mientras viva la citada mi mujer no se le prive del absoluto disfrute de dicha suerte ${ }^{27}$.

Esta protección hacia las colonas viudas, que en modo alguno dejaba desprotegidos a los hijos pues se les solía fijar una renta anual, hizo que durante gran parte del periodo foral en las Nuevas Poblaciones de Sierra Morena y Andalucía el sector femenino tuviera un grado de autonomía significativamente mayor que el existente en las localidades del entorno, aquejadas por lo general por una abundante masa de población jornalera. Incluso en aquellos casos en los que las colonas optaban por ceder la gestión directa de esos bienes a sus hijos, se garantizaban una renta anual que aseguraba dicha protección ${ }^{28}$. Una práctica que era habitual también en los casos de aquellas colonas que, siendo mayores de edad, estaban solteras y no tenían tutor o de aquellas que simplemente decidían permanecer viudas ${ }^{29}$.

27. Archivo Notarial de Posadas -en adelante ANPO-, La Carlota, Escribano Miguel Muñoz, prot. 936, año 1814, ff. 178v-179r. Pedro Comerú, colono en esta misma nueva población, hará también referencia en su testamento, otorgado en 1817, a la costumbre existente de que las mujeres heredasen a sus maridos cuando las suertes de tierra se adquirían estando ya casadas (ANPO, La Carlota, Escribano Miguel Muñoz, prot. 934, año 1817, ff. 40r-42v). El origen más temprano de esta práctica lo encontramos en la disposición que dirigió Pablo de Olavide a su subdelegado en La Carlota el 26 de octubre de 1771 ordenando sobre las viudas de los colonos que han sido jefes de dotación que, "aunque la suerte corra bajo del nombre y dirección del hijo mayor -aunque este sea casado- si tiene a su madre viuda en su compañía, a ella debe reputarse como primer jefe de la suerte" (AHN, Inquisición, leg. 3602, s.f.).

28. Este fue el caso, por ejemplo, de la colona de San Sebastián de los Ballesteros María Quotrof, viuda de Benito Rot, que en febrero de 1778 cedió la suerte 38 de esa población a su hijo Antonio Rot por no poder ocuparse de su cultivo "por sus achaques y avanzada edad" a cambio de 300 reales anuales y, en caso de que su hija no la atendiese, procurarle casa y alimento mientras viviese (ANPO, La Carlota, Escribano Ignacio del Pozo, prot. 889, año 1778, s.f.); o de la colona de Fuente Palmera Juana Kible, viuda de Francisco Divis, la cual en agosto de 1803 decidió traspasar las suertes 255 y 259 del $4^{\circ}$ Departamento de esa colonia, que le correspondía disfrutar mientras viviera, a su hija María Divis, casada con Manuel Martínez, a cambio de que cada año de su vida le procurasen 25 fanegas de trigo y de que le dieran alojamiento en la casa de dotación (ANPO, La Carlota, Escribano Miguel Muñoz, prot. 928, año 1803, ff. 135r-137v).

29. Un ejemplo de esta última posibilidad es el de Verónica Quislerin, viuda sin hijos de Lorenzo Herman, que el 5 de junio de 1816 cedió su suerte de tierra situada en el Departamento $1^{\circ}$ de La Carlota, por su avanzada edad y no poder ya atenderla, a un sobrino de su marido a cambio de una renta anual (ANPO, La Carlota, Escribano Miguel Muñoz, prot. 933, año 1816, ff. 164r-166v). 


\section{La difícil adaptación a un nuevo medio: idioma y poblamiento disperso}

Los casi ocho mil individuos con los que se establecieron, a partir de 1767, las Nuevas Poblaciones de Sierra Morena y Andalucía eran originarios, en gran medida, de localidades enclavadas hoy en las regiones francesas de Alsacia y Lorena, en las regiones alemanas de Baden-Würtemberg y Palatinado y en varios cantones suizos como Uri y Tesino. Una circunstancia que llevó a que la mayor parte de ellos tuviera como lenguas maternas el alemán -con sus muchos dialectos- y el francés, y un pequeño porcentaje el italiano.

En el Fuero de Población, promulgado como norma suprema de esta joven provincia, se declaraba la intención de que los nuevos pobladores aprendieran la lengua española (artículo 74), pero a la vez se dejaba al arbitrio del superintendente la elección del tipo de poblamiento que más conviniera (artículo 7). En este sentido, Pablo de Olavide optó siempre que fue posible por un poblamiento disperso en virtud del cual los colonos vivían en sus lotes de tierra, cuidando sus cultivos, sus ganados y sus pertenencias. Un hecho que complicó bastante la intención de que esos extranjeros aprendieran la lengua española. Los hombres tenían, hasta cierto punto, mayor margen para viajar e interactuar con los españoles por sus actividades agrarias y ganaderas, pero el sector femenino, limitado básicamente al ámbito doméstico, apenas dispondría de ocasiones para aprenderlo más allá de sus viajes para oír misa en los días festivos y para participar en las celebraciones a las que fueran invitadas o tuvieran que acudir por conocer a los finados, en el caso concreto de los entierros.

No hablar nuestro idioma haría que muchas de esas mujeres Ilegadas del otro lado de nuestras fronteras llevasen una existencia discreta, incluso melancólica, no en vano, algunas referencias de los primeros tiempos de la colonización vincularon parte de los fallecimientos de estos colonos, relacionados mayoritariamente con la adaptación a un nuevo medio con un clima que facilitaba la difusión de episodios palúdicos, con la melancolía por encontrase lejos de sus tierras de origen ${ }^{30}$. Esta reclusión en su entorno doméstico es la clave que consideramos que explica el que apenas contemos con testimonios documentales relativos a las mencionadas colonas, pues el desconocimiento de otras lenguas, aparte del español, por parte de los miembros de la administración neopoblacional obligaba a que tuviesen que valerse casi siempre de intérpretes para relacionarse con ellas, por lo que estas raras veces acudían al escribano o a la administración, viendo muy limitada así su autonomía. Veamos un par de casos entre los pocos que hemos localizado en este sentido, pues hasta cuando querían otorgar sus últimas voluntades se enfrentaron con la referida barrera idiomática. El 6 de junio de 1800, la colona Úrsula Wicmaier, vecina de La

30. García Cano, M. I., La colonización de Carlos III en Andalucía. Fuente Palmera, 17681835. Córdoba 1982, p. 53; y Hermosilla Molina, A., Cien años de medicina sevillana. La Regia Sociedad de Medicina y Demás Ciencias, de Sevilla, en el siglo XVIII. Sevilla 1970, p. 508. 
Carolina, requirió la presencia del escribano de la capital para otorgar su testamento, pero a su llegada este se encontró con el problema de la lengua y nos lo describe así: "habiendo pasado a las casas de la morada de Nicolás Kapel, colono de esta capital, al efecto de hautorizar (sic) el testamento y última voluntad que la colona, también de ella, Úrsula Wicmairen quería hacer, encontré a la misma enferma en cama y con motivo de no entender el idioma alemán que hablaba hice comparecer a don Jacobo Reinhart, vecino y colono en esta misma capital, y (sic) intérprete nombrado por la Intendencia de estas dichas Poblaciones, para citado idioma $(. . .)^{\prime \prime 31}$. Un caso nada excepcional pues también en La Carlota, capital de las Nuevas Poblaciones de Andalucía, tendría lugar otro muy similar solo tres años más tarde. La colona Bárbara Henerin, originaria de Oermingen (Alsacia) y viuda de Nicolás Brunswick, manifestó en 1803 al escribano Miguel Muñoz no saber español, por lo que este último debió valerse para otorgar el documento de los colonos Miguel Lips y Juan Weber, que actuaron como intérpretes ${ }^{32}$.

Aunque ya habían transcurrido más de tres décadas desde su llegada a España, y la esperanza de vida entonces era significativamente menor a la actual, por lo que habían fallecido ya gran parte de los que no eran jóvenes a su llegada a nuestro país, muchas de esas mujeres no podían aún comunicarse en español y otras murieron sin haber podido hacerlo nunca. Buena prueba de ello es que las autoridades eclesiásticas de La Carlota, en fechas tan tardías como 1799, seguían solicitando la presencia de religiosos que entendieran la lengua alemana 33 para "confesar a los colonos alemanes que no pueden explicarse con nuestro idioma", siendo el sacerdote elegido en esa ocasión para tal menester el mismo que también atendía a los colonos alemanes en la colonia de Guarromán ${ }^{34}$. Incluso sabemos que unos pocos años antes se habían contabilizado en las colonias ubicadas dentro de la jurisdicción de la diócesis cordobesa un total de 98 colonos (46 hombres y 52 mujeres) que no podían comunicarse en español y otros 47 individuos que solo podían hacerlo medianamente ${ }^{35}$.

31. AHPJ, Protocolos de La Carolina, Escribano Francisco Delgado, prot. 6226, año 1800, ff. $110 \mathrm{r}-114 \mathrm{v}$.

32. ANPO, La Carlota, Escribano Miguel Muñoz, prot. 928, año 1803, ff. 85r-88v. Ni que decir tiene que la veracidad de lo consignado en este documento se supedita al juramento de los intérpretes de hacer una traducción correcta de los deseos de la testante, de ahí que el escribano consigne esta circunstancia pues al desconocer la lengua de esta no puede dar fe de que lo que dice en alemán se corresponda con la versión traducida.

33. Esto no implica que no hubiera entonces individuos que necesitaran esta misma atención en francés, pero esta era una lengua más difundida entre los intelectuales españoles, incluido el clero; por lo que se procuraba elegir a los que la dominaran de entre los que se presentaban a los concursos para proveer las vacantes.

34. Archivo General del Obispado de Córdoba -en adelante AGOC-, Despachos Ordinarios, caja 7117/01, exp. 28, doc. 3.

35. AGOC, Despachos Ordinarios, caja 7399. Véase Hamer Flores, A, "La extinción de una diversidad lingüística: la desaparición de lenguas europeas en las nuevas poblaciones de 
Unas cifras bastante elevadas si consideramos que en febrero de 1793 se registraron únicamente 264 extranjeros en esas mismas colonias ${ }^{36}$, por lo que si combinamos ambas informaciones estaríamos hablando de que, aunque el 45\% de ellos podía comunicarse entonces en español sin demasiada dificultad, más de un tercio de ellos (un 37\%) era incapaz todavía de hacerlo.

Suponemos que esa escasa participación de las mujeres en la vida pública también estuvo muy condicionada por el temor a ser engañadas o que se malinterpretasen sus deseos. Contamos con un interesante ejemplo en este sentido. Como no siempre se podía disponer de intérpretes, cuando el individuo manejaba algo de español se prescindía de ellos, un hecho que generó más de un malentendido. El 10 de noviembre de 1776, Ana María Gazmon, viuda de Daniel Kenig y colona en Santa Elena, acudió al escribano para ratificar la palabra de matrimonio que había dado en septiembre de 1776 a don Benito Sanmartín ante el provisor y vicario de Jaén y para retractarse de lo que constaba en las declaraciones que hizo en La Carolina "por no haberle explicado bien las preguntas (...) por estar algo tarda en el castellano", de resultas de lo cual había entendido que Sanmartín no volvería, por lo que trató de casarse con otro hombre ${ }^{37}$.

En otro orden de cosas, la cuestión de los matrimonios mixtos entre extranjeros y españoles ha sido recurrentemente referenciada, no pocas veces desde una óptica en exceso simplista, como indicador del grado de integración de las comunidades centroeuropeas en nuestro país. Es innegable que estos enlaces facilitaron el aprendizaje de la lengua española tanto al cónyuge extranjero como a su descendencia, pero consideramos incorrecto, cuando no temerario, establecer correlaciones directas entre su grado de integración y el que dichos enlaces se produjeran en fechas más tempranas ${ }^{38}$. En una sociedad agraria donde la unión matrimonial constituía un requisito de primer orden para tener más

La Carlota, Fuente Palmera y San Sebastián de los Ballesteros (siglos XVIII-XIX)". Arte, Arqueología e Historia 21 (2014), pp. 303-308.

36. Bernaldo de Quirós, C., Colonización y subversión en la Andalucía..., p. 52. El 26 de febrero de 1793 se contabilizaban en las Nuevas Poblaciones de Andalucía un total de 375 colonos extranjeros (143 en La Carlota, 111 en La Luisiana, 76 en Fuente Palmera y 45 en San Sebastián de los Ballesteros).

37. AHPJ, Protocolos de La Carolina, Escribano Lázaro Ribera, prot. 6221, año 1776, ff. $66 r-67 r$.

38. A modo de ejemplo, se esgrime como argumento de un mayor sentimiento de comunidad -influenciado por los frailes capuchinos alemanes- en San Sebastián de los Ballesteros el que el primer matrimonio mixto no se realizase hasta 1773 (Reder Gadow, M., "La mujer, protagonista en las Nuevas Poblaciones...", Congreso Internacional Nuevas Poblaciones de Sierra Morena y Andalucía y otras colonizaciones agrarias en la Europa de la llustración. Jaén 2018, p. 1557); circunstancia que no afirmamos ni desmentimos por completo pero que obviamente tuvo más que ver con el hecho de que en esa colonia solo había una familia española frente a casi sesenta extranjeras en esos años. 
opciones de recibir un lote de tierra, esos enlaces hemos de contemplarlos dentro de una estrategia de supervivencia; la edad ${ }^{39}$ y la nacionalidad del contrayente serían un elemento relativo si no había disponible otra opción mejor en el mercado matrimonial ${ }^{40}$. Este hecho explica bastante bien que su significación porcentual no fuera muy elevada e incluso que algunas de esas parejas apenas pudieran comunicarse entre sí inicialmente ${ }^{41}$. Aún más, estos enlaces se verían impulsados también por el fenómeno de la viudez, que se hizo muy presente en las nuevas colonias en los años iniciales: de un lado, la obligación de mantener cultivado el lote de tierra para no perderlo forzaba a menudo a las viudas a contraer nuevas nupcias $y$, de otro, cuando enviudaban los hombres y quedaban a su cargo hijos pequeños, la urgencia de procurarles atenciones incentivaban cortos periodos de viudedad.

Las españolas también se enfrentaron, aunque en menor medida, una realidad similar. No tuvieron, ciertamente, el problema de una cultura y una lengua diferentes ${ }^{42}$, pero vivirían durante décadas la soledad y la inseguridad de ese poblamiento disperso por los términos de las colonias. Solo aquellas que residieron en las aldeas y lugares de población disfrutarían de una existencia con mayor interacción social. En este sentido, se produjeron significativas diferen-

39. No son infrecuentes los casos de matrimonios con significativas diferencias de edad entre los cónyuges, aunque entre ellos escasean, como era habitual en el resto del país, aquellos en los que las mujeres son las de mayor edad. Podía darse el caso de que los maridos duplicasen la edad de sus esposas, como ocurrió en un matrimonio de Aldeaquemada en el que el contrayente, Melchor Steiner, tenía 56 años frente a los 27 de la contrayente, Francisca Boitiperin (Sánchez-Batalla Martínez, C., Aldeaquemada: arte, naturaleza..., p. 197).

40. Aún más, al igual que en el resto del Estado, desde la real cédula de 31 de mayo de 1783 se sumaría el requisito forzoso de que los contrayentes dispusiesen de consentimiento paterno (declarándose incluso al año siguiente que los que se casaran sin tal consentimiento incurrían en pecado mortal), una circunstancia que relegaría todavía más a un segundo plano el amor como principal causa para los enlaces. La herencia y las estrategias familiares se situaron con claridad en un primer plano (Aguirre, S., Prontuario alfabético y cronológico por orden de materias de las instrucciones, ordenanzas, reglamentos, pragmáticas y demás reales resoluciones no recopiladas que han de observarse para la administración de justicia y gobierno de los pueblos del Reino. Madrid 1794, tomo 1, p. 322).

41. La documentación, aunque muchas veces llega a obviar la presencia de los intérpretes en las declaraciones de los colonos extranjeros por lo habitual que esta era, nos deja también numerosas evidencias de que hubo matrimonios mixtos en los que ambos cónyuges desconocían la lengua del otro. Sirva como ejemplo el enlace realizado en La Carlota el 15 de julio de 1770 entre Alonso Cáliz, vecino de la cercana localidad de Fernán Núñez, y Barbara Dietterhoferin, colona viuda de La Carlota y originaria de Alsacia; pues en éste mientras que el contrayente pudo comunicarse sin problema con el sacerdote español que ofició la boda, la contrayente necesitó que actuase como intérprete el religioso suizo Felix Nagel (Archivo Parroquial de La Carlota -en adelante APLC-, Libro 1 de Matrimonios, f. 21r).

42. Carecemos de testimonios documentales que lo avalen, pero las zonas de origen de algunas de estas familias españoles se encontraban en Cataluña y en el Reino de Valencia, por lo que podemos suponer que algunos hablaban catalán y valenciano. En cualquier caso, difícilmente serían incapaces de manejarse en la lengua española. 
cias entre los dos partidos territoriales de las Nuevas Poblaciones pues, aunque inicialmente se procuró el poblamiento disperso en todas ellas, con cierta rapidez las de Sierra Morena tendieron a reducir a su mínima expresión ese tipo de poblamiento mientras que en las de Andalucía se mantuvo ${ }^{43}$.

En cualquier caso, no todo fue negativo en esa barrera lingüística y ese aislamiento de las colonas extranjeras pues, en nuestra opinión, esos factores contribuirían decisivamente a que se mantuvieran durante décadas diversos elementos que formaban parte de la cultura y tradiciones centroeuropeas como fueron las vestimentas femeninas ${ }^{44}$, ya que en el sector masculino la indumentaria se adaptó rápidamente a la moda española, y algunas costumbres como, por ejemplo, la de los huevos de Pascua ${ }^{45}$. Es de sobra conocido que son las mujeres las verdaderas protagonistas en el mantenimiento de elementos culturales en las sociedades preindustriales, de ahí que su lenta asimilación a la cultura española facilitara la pervivencia de esas prácticas.

\section{Las colonas como objeto del arte: entre la mujer laboriosa y la madre de familia}

En una época en la que aún faltaban varias décadas para la difusión de la fotografía y en la que costear una pintura estaba solo al alcance de los que podían pagar su elevado precio, las posibilidades de que unas familias establecidas en una colonización agraria protagonizaran representaciones artísticas eran muy escasas. Esta comunidad de medianos propietarios agrícolas no tendría entre sus preferencias el costear retratos, una práctica vinculada entonces a sectores sociales más acaudalados y relacionados con el gobierno y la administración. De ahí que no contemos con ninguna pintura o similar hecha por encargo de los propios colonos y en los que pudieran haber sido incluidos, ni siquiera en la modalidad de exvotos religiosos pues esta costumbre de agradecer con representaciones pictóricas la gracia concedida por el titular de la capilla o el altar correspondiente no estuvo presente en las Nuevas Poblaciones de Sierra Morena y Andalucía. Las posibilidades de poder contemplar con nuestros ojos a aquellos colonos, tanto hombres como mujeres,

43. Hamer Flores, A., "Un ensayo de poblamiento disperso. Las Nuevas Poblaciones de Sierra Morena y Andalucía (siglos XVIII-XIX)", Bolós, J. y Vicedo, E. (coords.), Poblament, territori i història rural. VI Congrés sobre Sistemes Agraris, Organització Social i Poder Local. Lleida 2009, pp. 677-693.

44. A mediados del siglo XIX, J. Guichot describe el traje que llevaban algunas mujeres de La Carlota como muy similar a los que eran tradicionales en las regiones centroeuropeas de las que procedían sus antepasados (Hamer Flores, A., La Carlota en los relatos de viajeros y escritores de los siglos XVIII y XIX. Madrid 2009, p. 106).

45. Esta tradición vinculada con la Semana Santa sigue viva, dos siglos y medio después, entre muchos de los descendientes de aquellos colonos extranjeros. 
se reducen, pues, a que algún organismo o particular decidiese incluirlos en alguna obra.

Lejos de lo que a priori pudiera pensarse, el hecho de que esta colonización agraria fuera promovida directamente por la Corona no implicó una mejor visualización del proyecto y de sus protagonistas. La publicidad gubernamental de esta iniciativa fue sorprendentemente escasa a pesar del interés que suscitó y de la considerable inversión que supuso, tal vez como resultado de la simbiosis del temor a un temprano triunfalismo y de una serie de hechos adversos que la dificultaron. Una iniciativa de esta envergadura, en la que las dificultades no fueron escasas durante los primeros años, aconsejaba prudencia para evitar el descrédito que la Corona habría experimentado si el proyecto hubiera fracasado tras haber sido ampliamente difundido. En la memoria de sus promotores, sin duda, estuvieron presentes otros proyectos de colonización europeos cuyo fracaso deterioró notablemente la imagen del Estado promotor; destacando quizá entre ellos, por su proximidad temporal y espacial, el de la colonización francesa en la Guyana y algunas islas de las Antillas desarrollado a comienzos de esa misma década. Una iniciativa que, a pesar de todos los recursos materiales y humanos empleados, fracasó estrepitosamente, Ilegándose a trasladar de vuelta al continente europeo a gran parte de los colonos que sobrevivieron a la mortalidad catastrófica de la que fueron víctimas ${ }^{46}$. Del mismo modo, entre esas dificultades iniciales del proyecto neopoblacional destacó la visita de inspección en 1769 de Pedro José Pérez Valiente, que asestó un duro golpe a la credibilidad de la iniciativa y de sus promotores, especialmente del superintendente Pablo de Olavide $^{47}$. Tanto es así que hasta 1774, momento en el que se impulsaron los proyectos de ubicar una estatua de Carlos III en La Carolina ${ }^{48}$, una de las dos capitales de las nuevas colonias, y de realizar una medalla conmemorativa de la colonización ${ }^{49}$, se mantendría un perfil bastante discreto al hablar de ellas. El

46. La bibliografía sobre esta iniciativa colonizadora francesa es muy amplia, pero destacamos aquí dos títulos de imprescindible lectura: Godfroy, M., Kourou, 1763. Le dernier rêve de l'Amérique française. Paris 2011; y Thibaudault, P., Échec de la démesure en Guyane. Autour de l'expédition de Kourou, une tentative européenne de réforme des conceptions coloniales sous Choiseul. Lezay 1995.

47. La visita de Pérez Valiente fue objeto de análisis hace más de dos décadas en dos meritorios trabajos: Castilla Soto, J., "Las Nuevas Poblaciones de Sierra Morena bajo la superintendencia de don Pedro Pérez Valiente: oficios y colonos". Espacio, tiempo y forma. Historia Moderna 5 (1992), pp. 283-296; y Vallejo García-Hevia, J. M., "Campomanes y las Nuevas Poblaciones de Sierra Morena y Andalucía (1766-1793)". Boletín del Instituto de Estudios Giennenses 163 (1997), pp. 254-279.

48. AGS, Secretaría y Superintendencia de Hacienda, leg. 498, doc. 321. Carta de Múzquiz a Olavide, 23 de julio de 1774. A pesar de las numerosas gestiones que se realizaron, esta estatua nunca llegó a realizarse.

49. El 1 de mayo de 1774 el secretario de Estado, marqués de Grimaldi, encargó al director de la Real Academia de la Historia, Pedro Rodríguez de Campomanes, una medalla conmemorativa de la colonización de Sierra Morena. Tras la realización de varias propuestas, que 
golpe definitivo, no obstante, tendría lugar a finales de 1778 cuando la Inquisición sentenció como hereje formal y miembro podrido de la religión a Pablo de Olavide $^{50}$. Esta condena al principal promotor de las nuevas colonias supuso un punto de inflexión definitivo en la visualización del proyecto que, salvo casos puntuales, no volverá a ser reivindicado como un éxito del reinado de Carlos III durante varias décadas.

De todos modos, estas adversidades no han impedido que contemos con varias representaciones de colonas datadas en el marco temporal comprendido entre 1768 y 1805 . Como era de esperar, ninguna de ellas fue realizada por mujeres o se debió a su iniciativa, de ahí que constituyan un interesante testimonio acerca de las diferentes visiones que sobre ellas se tuvieron o que se trataron de difundir. Para su análisis podemos distinguir dos bloques, situándose en el primero aquellas de carácter realista y que, en principio, muestran escenas habituales en la vida cotidiana; mientras que en el segundo encontramos otras, mucho más tardías, en las que el rol predominante es el de esposas y madres.

En los inicios de la colonización, concretamente en 1768, el subdelegado de las Nuevas Poblaciones de Sierra Morena, Miguel de Jijón, decidió levantar unas torres de piedra para adornar la entrada de La Carolina, colocando en ellas seis placas con relieves e inscripciones, en las que dos de ellas mostrarían a los nuevos pobladores ${ }^{51}$. En la placa central de la torre de la izquierda se representarían labores eminentemente masculinas como las de desmonte y cultivo de terrenos, mientras que en la situada en igual posición de la torre de la derecha se incluyeron tareas consideradas femeninas como eran el lavado

se guardan en el archivo de esta institución, se aceptó la de Tomás Francisco Prieto y Jerónimo Antonio Gil (Almagro Gorbea, M., Pérez Alcorta, M. C. y Moneo, T., Medallas españolas. Catálogo del Gabinete de Antigüedades. Madrid 2005, pp. 535-537).

50. Sobre la caída y proceso inquisitorial de Olavide destacan los recientes trabajos de Gómez Urdáñez, J. L., "Con la venia de Carlos III. El castigo ejemplar de Olavide, consecuencia de la venganza de Grimaldi contra el conde de Aranda". Vegueta. Anuario de la Facultad de Geografía e Historia 15 (2015), pp. 373-400; y "Amigos y enemigos. Grimaldi, Ventura Figueroa, Ensenada, Aranda y... Olavide", Iglesias Rodríguez, J. J. (coord.), Comercio y cultura en la Edad Moderna. Actas de la XIII Reunión Científica de la Fundación Española de Historia Moderna. Sevilla 2015, vol. 2, pp. 2115-2127.

51. El superintendente Pablo de Olavide, al ver concluidas estas dos torres, decidió realizar algunos cambios porque consideró que podrían malinterpretarse y ser usadas en su contra por sus detractores; y no se equivocaba. Aunque mandó quitar la placa en la que él mismo aparecía en gesto de ofrecer la nueva colonia a Carlos III, sustituyéndola con otra de la Inmaculada Concepción, y las dos que contenían las inscripciones, el visitador Pedro José Pérez Valiente dio cuenta de estos elementos al gobierno. Por orden suya se sustituiría la placa de la Inmaculada Concepción, que fue trasladada a la fachada de la iglesia, por un relieve representando al príncipe heredero Carlos, futuro Carlos IV. Estas dos torres se conservan en la actualidad en La Carolina, aunque fueron trasladadas a una nueva ubicación a comienzo del paseo del Molino de Viento en el siglo XIX, con las cuatro placas que se consideraron como las definitivas en 1769. 
de la ropa y la recogida de agua en fuentes y pozos (Figura 1). El deterioro derivado de haber estado expuestas a las inclemencias meteorológicas durante dos siglos y medio nos impide conocer el nivel de detalle con el que se esculpieron originalmente las figuras, pero todavía es posible identificar las vestimentas femeninas e incluso los peinados. Aunque el objetivo de estas dos representaciones era eminentemente propagandístico, al mostrar a vecinos y visitantes los logros y avances de esta iniciativa ilustrada, disponemos de dos escenas que, más allá de visualizar parte de la vida cotidiana de sus habitantes, constituyen un claro reflejo del ya mencionado pensamiento de Olavide. Las mujeres tendrían un papel activo en el funcionamiento y éxito de las colonias, de ahí la necesidad de representarlas en un interesante ejercicio de igualdad con las labores masculinas y no simplemente invisibilizarlas en el conjunto de la sociedad neopoblacional.

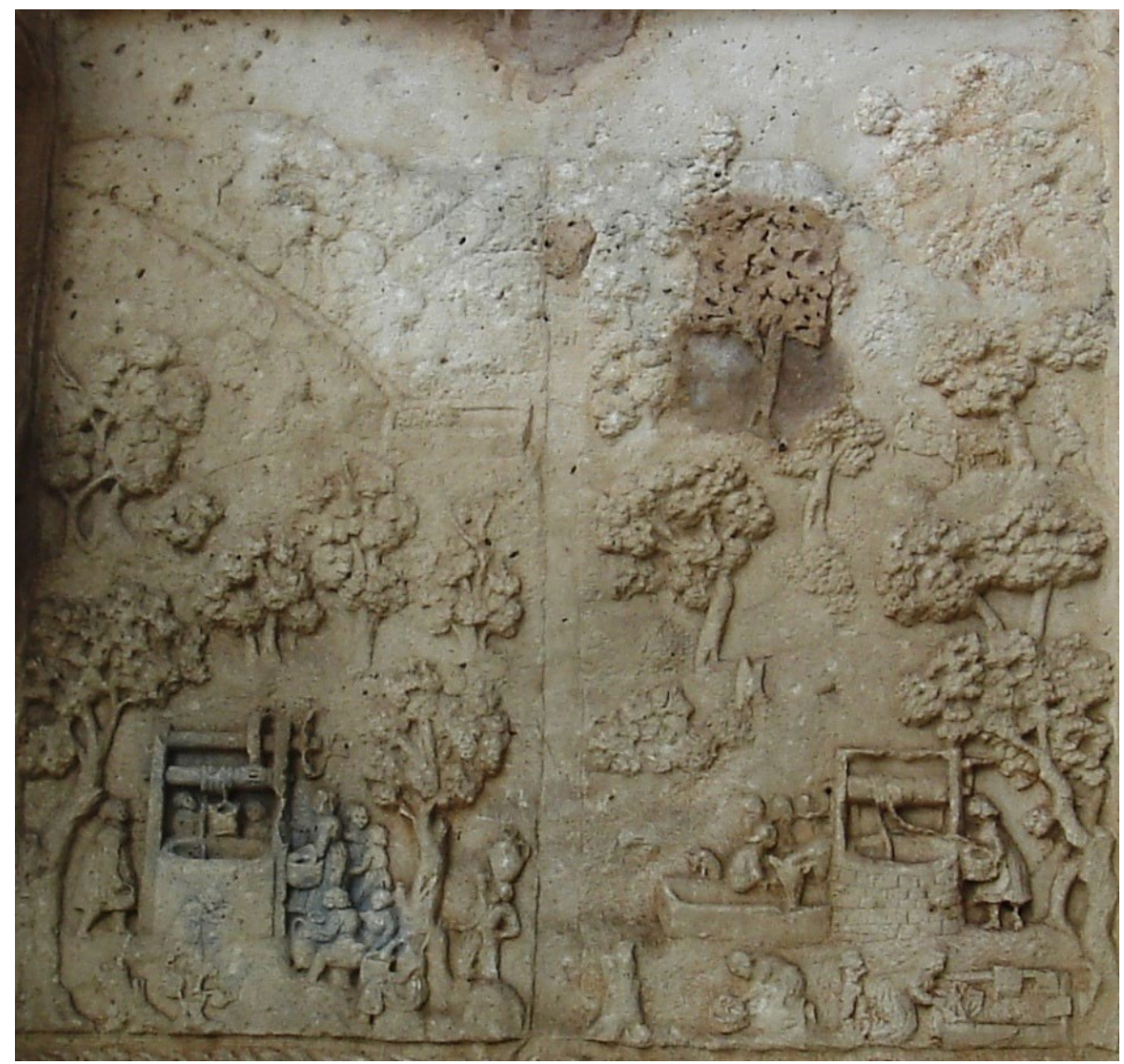

Figura 1. Placa con relieve alusivo a las labores femeninas (La Carolina, Jaén). 
Otra representación de carácter realista nos la brinda el inglés Henry Swinburne que, en su viaje por nuestro país en 1775 y 1776, dibujó al natural una escena campestre en las proximidades del castillo de Tolosa, en La Carolina (Figura 2). Por suerte, este dibujo estuvo entre los elegidos para convertirse en uno de los grabados de la obra impresa en la que Swinburne daba cuenta de su estancia en España, haciendo posible que hoy dispongamos de esta estampa popular ${ }^{52}$. En ella se puede observar a un grupo de personas adultas, estando presentes tanto hombres como mujeres, ataviadas con indumentaria festiva en lo que parece ser una costumbre, vigente hasta no hace mucho tiempo, de los vecinos de los núcleos de población cercanos (La Carolina y Navas de Tolosa, fundamentalmente) de disfrutar de jornadas de ocio en este paraje. A diferencia de los relieves que analizábamos antes, en este caso la inclusión de las mujeres obedece simplemente a su participación en estas actividades lúdicas, fundamentales para la sociabilidad y el fomento de relaciones que culminasen en matrimonio.

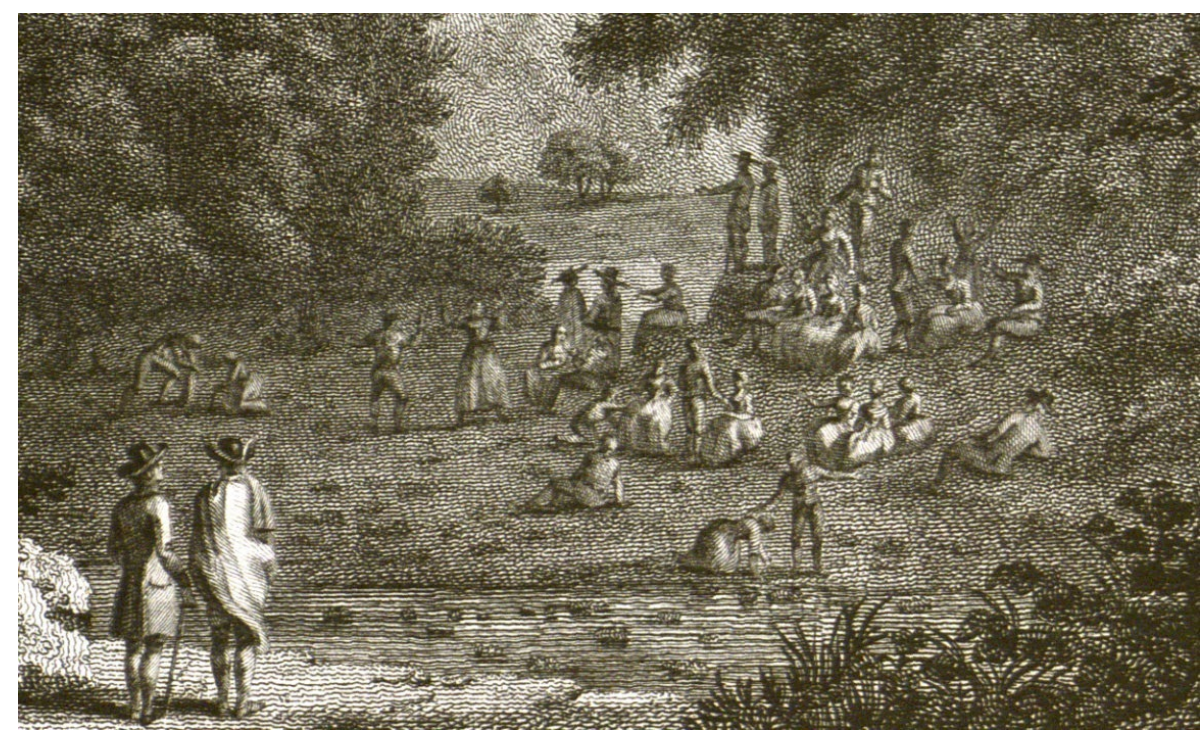

Figura 2. Detalle de una escena campestre en las proximidades del castillo de Tolosa (La Carolina).

52. Para esta investigación hemos utilizado el grabado al aguafuerte titulado "Ruins of the Castle of Las Navas in Andalusia" incluido en Swinburne, H., Picturesque Tour through Spain. Embellished with Twenty Engravings, by Watts, Medland, Angus, Mitan, \& c. London, Edward Orme, 1806. La primera edición de esta obra apareció en Londres en 1779. 
En otro orden de cosas, el segundo bloque de representaciones femeninas nos lleva hasta 1805 y está vinculado a un concurso de pintura. La Real Academia de Bellas Artes de San Fernando (Madrid) convocaría una vez más el ya tradicional concurso entre sus alumnos, fijando ese año para la primera clase de la sección de pintura el tema:

Carlos Tercero acompañado de la Beneficencia y la Agricultura entrega los terrenos de Sierra Morena a colonos de varias castas para que los pueblen y cultiven. A lo lejos, y huyendo del sol, que presencia esta acción, se ven entre tinieblas ladrones y forajidos que abandonan este sitio.

Se presentaron ocho opositores al concurso, conservándose en la actualidad cinco pinturas, entre ellas las tres mejor valoradas. En la primera votación del jurado se produjo un empate entre las obras de José Alonso del Ribero y de José de Odriozola, que se resolvió claramente a favor del primero en una segunda votación. El segundo premio fue para el mencionado Odriozola, quedándose la obra de Victoriano López a un solo voto del empate ${ }^{53}$.

El Museo de la Real Academia de Bellas Artes de San Fernando, como cabía esperar, conserva entre sus fondos ese "Carlos III entregando tierras a los colonos de Sierra Morena" de Ribero y el titulado "Carlos III con el hábito de la Orden de su nombre recibiendo a los colonos de Sierra Morena" de Odriozola ${ }^{54}$. No ocurre lo mismo, en cambio, con los otros tres cuadros, estando en nuestros días solo dos de ellos depositados en instituciones públicas. El presentado al concurso por Victoriano López forma parte de los fondos del Alcázar de Segovia $^{55}$, mientras que el pintado por Francisco Lacoma y Sans se ubica en la Real Academia Catalana de Bellas Artes de San Jorge (Barcelona) ${ }^{56}$. Finalmente, el titulado "Alegoría de la colonización de Sierra Morena por Pablo de Olavide en el reinado de Carlos III", de Felipe Abás, se encuentra en la colección privada de la familia Sanz Fuertes (Zaragoza).

Como era de esperar, estos cinco autores concederían en sus obras un elevado protagonismo a la figura del monarca y a la de las alegorías de la Agricultura y la Beneficencia, hasta el punto de que en la pintura ganadora los colonos

53. Distribución de los premios concedidos por el rey nuestro señor a los discípulos de las tres nobles artes, hecha por la Real Academia de San Fernando en la Junta pública de 27 de julio de 1805, Madrid, En la Imprenta de la Hija de Ibarra, 1805, pp. 29-30, 34 y 38-39.

54. La pintura de Rivero está inventariada con el número 254 y tiene unas dimensiones de $168 \mathrm{~cm}$ de alto y $126 \mathrm{~cm}$ de ancho; y la de Odriozola lo está con el número 1069 y tiene unas dimensiones de $100 \mathrm{~cm}$ de alto y $140 \mathrm{~cm}$ de ancho. Ambas son óleos sobre lienzo.

55. "Carlos III funda la colonia de Despeñaperros". Número de inventario 153. Óleo sobre lienzo con unas dimensiones de 124,5 cm de alto y $167 \mathrm{~cm}$ de ancho.

56. "Carlos III ejecutando el proyecto de poblar Sierra Morena". Número de inventario 329. Óleo sobre lienzo con unas dimensiones de $126 \mathrm{~cm}$ de alto y $168 \mathrm{~cm}$ de ancho. 
representados son minoría frente a otros miembros del gobierno y la administración, fácilmente identificables en casos como Pedro Rodríguez de Campomanes o Pablo de Olavide. Enfoque similar al empleado por Felipe Abás, aunque en este caso el pintor procura que los colonos ocupen buena parte de la escena. Mayor presencia, en cambio, les concedieron el resto de los concursantes en los suyos al prescindir de esos miembros del gobierno, lo que no impide que sigan siendo representaciones claramente idealizadas. Frente al realismo de los relieves de La Carolina, en estas obras de 1805 los rasgos físicos y las vestimentas reflejadas son los de cualquier español; aunque poniendo especial énfasis en que las ropas tuvieran un aspecto cuidado y que parecieran ser las que usaban en días de fiesta, de ahí la profusión de unos colores que difícilmente estarían a su alcance en el día a día. En cualquier caso, ello no sería impedimento para que los dos premiados representaran a los colonos descalzos, probablemente para simbolizar que el monarca velaría por su bienestar y los calzaría.

Ser fieles a los rasgos físicos del rey y de otros personajes destacados no era muy difícil a comienzos del siglo XIX en un entorno tan vinculado a las artes, pues los estudiantes tendrían acceso a retratos y grabados; no obstante, mostrar o incluso conocer los rasgos concretos de esa población de origen mayoritariamente centroeuropeo estando tan alejados de las colonias era muy complejo y quizá no preocupó en demasía a los autores de las obras. Lo representado se corresponde con una idealización. No obstante, sí nos parece muy interesante el distinto tratamiento que se da a esos colonos en ellos ya que de ello se deriva una visión u otra del rol femenino. La unidad familiar compuesta por marido, mujer e hijo(s) adquiere un papel destacado en las obras de José Odriozola y Felipe Abás al convertirla en la cabeza de la comitiva de colonos e incluso, como ocurre en el caso de Odriozola, concediéndoles un destacado protagonismo al representar al jefe de familia besando la mano a Carlos III. En ambos casos, la mujer es situada en un plano secundario y vinculada directamente a sus hijos, mostrando con claridad un papel de mujer fértil que garantizaría el aumento de la población y la riqueza de las colonias. Una estrategia similar emplea Victorino López, aunque en su caso prefiere representar a varios colonos y colonas jóvenes, sin incluir ningún niño.

El cuadro que recibió el primer premio es quizá el que menos atención presta a los colonos incluidos, desplazándolos a un segundo plano y concediendo un gran protagonismo a los útiles agrarios que portan. Las mujeres representadas son pocas y en espacios casi marginales, dejando claro que Ribero quiso hacer hincapié en la visión de esos pobladores como instrumento para la riqueza del país; un espacio laboral en el que las mujeres no parecen tener mucha importancia. Finalmente, el trabajo surgido de los pinceles de Francisco Lacoma nos muestra un enfoque muy interesante ya que otorga protagonismo a los hijos pequeños de los colonos, que son conducidos hacia el monarca, aunque con ello las colonas son desplazadas a la periferia de la escena, adoptando ellas además poses encorvadas en la mayor parte de los casos representados. 


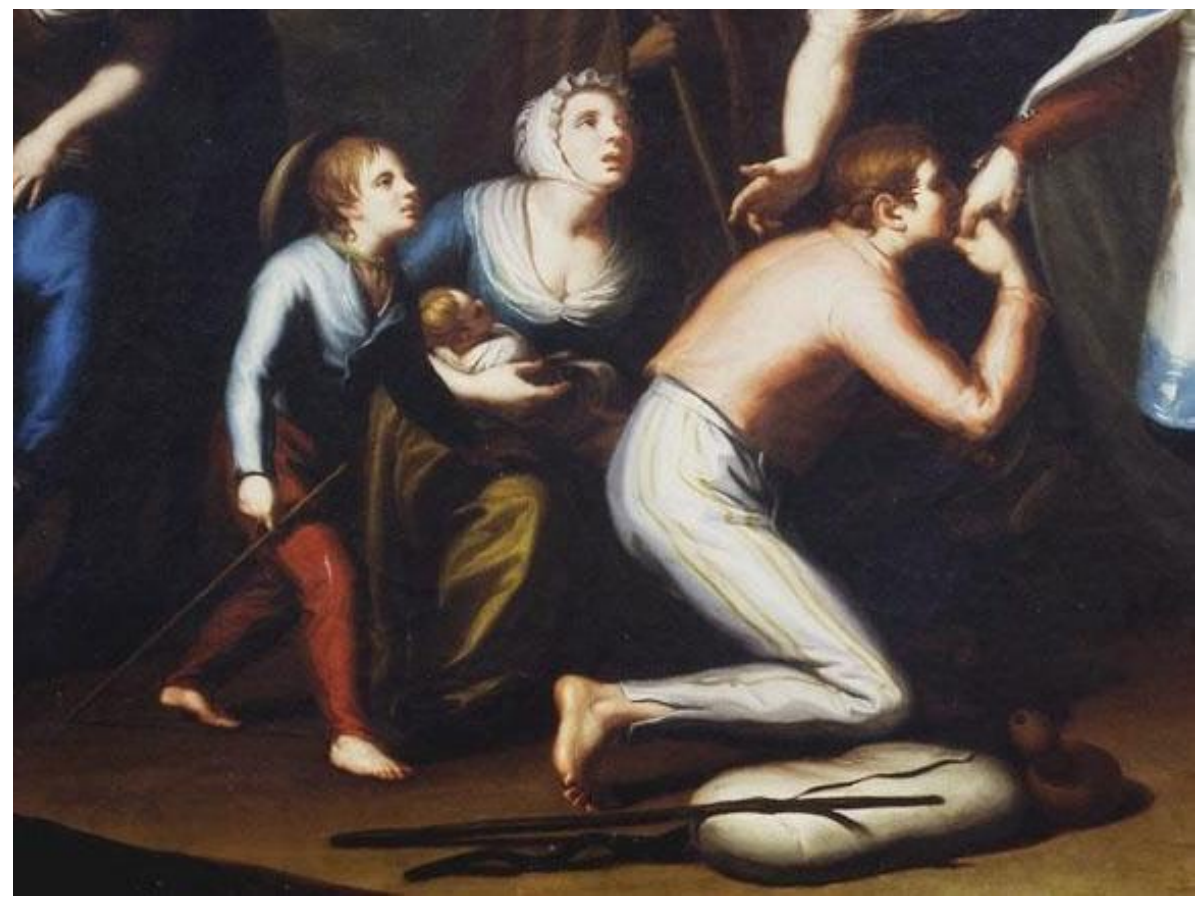

Figura 3. Detalle de la pintura de José Odriozola (1805). Real Academia de Bellas Artes de San Fernando.

Todo ello nos permite concluir que las mujeres representadas en 1805 se ajustan al rol de esposa y madre de familia. Esa fiel colaboradora de su marido que garantiza una abundante progenie que incremente con su trabajo la riqueza de la monarquía. Lejos quedaba ya esa apuesta inicial de las autoridades neopoblacionales por impulsar y visualizar las labores domésticas y el trabajo de la mujer en la nueva sociedad que se pretendía establecer a partir de 1767, que no solo se interrumpió en las propias colonias, sino que tampoco logró superar sus límites jurisdiccionales.

\section{Conclusiones}

La fundación de las Nuevas Poblaciones de Sierra Morena y Andalucía a finales del siglo XVIII empleando como material humano a familias de origen centroeuropeo implicó en el tema que aquí nos ocupa, la mujer y el ámbito familiar, una serie de problemáticas y peculiaridades que se sumaron a las que ya de por sí estaban presentes en otros puntos comarcanos. Cuestiones como el idioma supusieron una verdadera barrera para la interacción 
con los hispanohablantes, realidad más evidente si cabe en el caso de las mujeres extranjeras y agravado además por la existencia de un poblamiento disperso. De ahí que muchas de aquellas mujeres que llegaron entre 1767 y 1769 a España desde diversos puntos de las actuales Alemania, Suiza y Francia, vivieran en nuestro país durante décadas y hasta su fallecimiento casi aisladas. Sus contactos se limitarían casi a su propia familia y a los vecinos que manejaran su mismo idioma, los cuales, con el paso del tiempo, cada vez serían menos por razones biológicas. Además, el poco o escaso manejo de la lengua española las expondría a no pocos malentendidos que, en la medida que les era posible, tratarían de evitar usando como intermediarios a hombres, que tenían más facilidad para aprender español. Circunstancia que mermaba, todavía más, su autonomía.

En lo que concierne al papel que la administración neopoblacional concedió a las mujeres en estas colonias, podemos destacar la decidida apuesta que el superintendente Pablo de Olavide hizo en los años iniciales por incorporarlas a la economía productiva, tanto en las labores agrarias como en las actividades artesanales e industriales. Un incremento de la mano de obra, perfectamente compatible con atender adecuadamente su hogar, que aumentaría la riqueza de la nueva provincia y los recursos de las familias; y que además, dicho sea de paso, haría de las Nuevas Poblaciones un interesante campo de ensayo de iniciativas vinculadas con los inicios de la industrialización. Lamentablemente, la caída de Olavide en 1776 implicó la práctica desaparición de estas iniciativas, perviviendo únicamente algunos rasgos que tenían en cuenta al sector femenino recogidos en el Fuero de Población. Cuestiones relacionadas, sobre todo, con la propiedad y tenencia de la tierra en las nuevas colonias.

Finamente, las mujeres y las familias de las Nuevas Poblaciones también tuvieron su espacio en el mundo del arte. Los testimonios, como era de esperar, son muy escasos, pero sitúan a las unidades familiares en su conjunto, no solo a los hombres, como protagonistas de esa colonización agraria. La mujer en las colonias, especialmente durante la superintendencia de Pablo de Olavide, tuvo un papel en el espacio público hasta entonces ocupado mayoritariamente por el sector masculino, de ahí que se plasmasen sus actividades cotidianas en una de las torres conmemorativas de la fundación erigidas en La Carolina; pero fuera de esta jurisdicción, como puede apreciarse en los cuadros presentados al concurso de 1805 en la Real Academia de Bellas Artes de San Fernando, la visión de la mujer se reducirá básicamente a su rol de madre y esposa. Prueba evidente de la escasa repercusión que tuvieron todas esas iniciativas en pro de una mayor visualización y variedad del rol femenino fuera del ámbito estrictamente provincial de las nuevas colonias. 


\section{Bibliografía}

Aguirre, S., Prontuario alfabético y cronológico por orden de materias de las instrucciones, ordenanzas, reglamentos, pragmáticas y demás reales resoluciones no recopiladas que han de observarse para la administración de justicia y gobierno de los pueblos del Reino. Madrid, Oficina de don Benito Cano, $2^{a}$ impresión, 1794.

Almagro Gorbea, M., Pérez Alcorta, M. C. y Moneo, T., Medallas españolas. Catálogo del Gabinete de Antigüedades. Madrid 2005.

Bernaldo de Quirós, C., Colonización y subversión en la Andalucía de los s. XVIII-XIX. Barcelona 1986.

Castilla Soto, J., "Las Nuevas Poblaciones de Sierra Morena bajo la superintendencia de don Pedro Pérez Valiente: oficios y colonos". Espacio, tiempo y forma. Historia Moderna 5 (1992), pp. 283-296.

Defourneaux, M., Pablo de Olavide, el afrancesado. México 1965.

Discurso sobre el fomento de la industria popular. Madrid, Imprenta de don Antonio de Sancha, 1774.

Distribución de los premios concedidos por el rey nuestro señor a los discípulos de las tres nobles artes, hecha por la Real Academia de San Fernando en la Junta pública de 27 de julio de 1805. Madrid, En la Imprenta de la Hija de Ibarra, 1805.

García Cano, M. I., La colonización de Carlos III en Andalucía. Fuente Palmera, 1768-1835. Córdoba 1982.

Godfroy, M., Kourou, 1763. Le dernier rêve de l'Amérique française. Paris 2011.

Gómez Navarro, M. S., "Aportación para una doble efeméride: Carlos III y su obra colonizadora en las prensas. Un estado de la cuestión". Revista de Historiografía 27 (2017), pp. 363-381.

Gómez Urdáñez, J. L., "Con la venia de Carlos III. El castigo ejemplar de Olavide, consecuencia de la venganza de Grimaldi contra el conde de Aranda". Vegueta. Anuario de la Facultad de Geografía e Historia 15 (2015), pp. 373400.

Gómez Urdáñez, J. L., "Amigos y enemigos. Grimaldi, Ventura Figueroa, Ensenada, Aranda y... Olavide", Iglesias Rodríguez, J. J. (coord.), Comercio y cultura en la Edad Moderna. Actas de la XIII Reunión Científica de la Fundación Española de Historia Moderna. Sevilla 2015, vol. 2, pp. 2115-2127.

Hamer Flores, A., La Carlota en los relatos de viajeros y escritores de los siglos XVIII y XIX. Madrid 2009.

Hamer Flores, A., "Un ensayo de poblamiento disperso. Las Nuevas Poblaciones de Sierra Morena y Andalucía (siglos XVIII-XIX)", Bolós, J. y Vicedo, E. (coords.), Poblament, territori i història rural. VI Congrés sobre Sistemes Agraris, Organització Social i Poder Local. Lleida 2009, pp. 677-693. 
Hamer Flores, A., "La extinción de una diversidad lingüística: la desaparición de lenguas europeas en las nuevas poblaciones de La Carlota, Fuente Palmera y San Sebastián de los Ballesteros (siglos XVIII-XIX)". Arte, Arqueología e Historia 21 (2014), pp. 303-308.

Hamer Flores, A., "Orden y vida cotidiana en la Intendencia de las Nuevas Poblaciones de Sierra Morena y Andalucía. El frustrado auto de buen gobierno de 1801". Codex. Boletín de la Ilustre Sociedad Andaluza de Estudios Histórico-Jurídicos 6-7 (2014-2016), pp. 139-163.

Hamer Flores, A. (ed.), Legislación Histórica Neopoblacional. Disposiciones normativas emanadas del poder central en las Nuevas Poblaciones de Sierra Morena y Andalucía (1767-1835). Madrid 2018.

Hermosilla Molina, A., Cien años de medicina sevillana. La Regia Sociedad de Medicina y Demás Ciencias, de Sevilla, en el siglo XVIII. Sevilla 1970.

Lluch, E. y Argemí, L., "Genealogía teórica e influencia práctica del Discurso sobre el fomento de la industria popular (1774)". Revista de Historia Industrial 3 (1993), pp. 179-190.

Perdices de Blas, L., Pablo de Olavide (1725-1803), el ilustrado. Madrid 1992.

Perdices de Blas, L., "Mujeres, educación y mercado de trabajo en el proyecto reformista de Pablo de Olavide", ICE. Revista de Economía 852 (enero-febrero 2010), pp. 99-111.

Reder Gadow, M., "La mujer, protagonista en las Nuevas Poblaciones de Carlos III", Congreso Internacional Nuevas Poblaciones de Sierra Morena y Andalucía y otras colonizaciones agrarias en la Europa de la Ilustración. Jaén 2018, pp. 1549-1567.

Rodríguez-Moñino Soriano, R., "Presencia de la mujer en las Nuevas Poblaciones de Sierra Morena y Andalucía". Boletín del Instituto de Estudios Giennenses 160 (1996), pp. 7-36.

Sánchez-Batalla Martínez, C., Aldeaquemada: naturaleza, arte e historia. Prehistoria a 1835. Jaén 1996.

Sánchez-Batalla Martínez, C., "Mujer, familia y vida cotidiana en las Nuevas Poblaciones", Mujer, familia y sociedad en las Nuevas Poblaciones. Actas del IV Congreso Histórico sobre Nuevas Poblaciones. La Carolina 1996.

Swinburne, H., Picturesque Tour through Spain. Embellished with Twenty Engravings, by Watts, Medland, Angus, Mitan, \& c. London, Edward Orme, 1806.

Thibaudault, P., Échec de la démesure en Guyane. Autour de l'expédition de Kourou, une tentative européenne de réforme des conceptions coloniales sous Choiseul. Lezay 1995.

Vacas Campos, S. M. y Vacas del Campo, J. A., "Las mujeres en las Nuevas Poblaciones", Congreso Internacional Nuevas Poblaciones de Sierra Morena y Andalucía y otras colonizaciones agrarias en la Europa de la Ilustración. Jaén 2018, pp. 1467-1483. 
Vallejo García-Hevia, J. M., "Campomanes y las Nuevas Poblaciones de Sierra Morena y Andalucía (1766-1793)". Boletín del Instituto de Estudios Giennenses 163 (1997), pp. 185-296.

Wollstonecraft, M., A vindication of the rights of woman; with strictures on political and moral subjects. Boston 1792. 